\title{
LA INVESTIGACIÓN BIOMÉDICA Y EL CONSENTIMIENTO INFORMADO EN EL ÁMBITO DE LAS POBLACIONES E INDIVIDUOS VULNERABLES
}

\author{
Susana la Rocca, Gladys Martínez, Alejandra Rascio y Mirta Bajardi*
}

\begin{abstract}
Resumen: El contexto de transnacionalidad económica y política en el que se desarrollan las actuales investigaciones biomédicas favorece el fenómeno conocido como "medicalización" de la vida y promueve la vulnerabilidad tanto de países como de individuos. Si tenemos en cuenta que es responsabilidad asumida por la bioética la preocupación por proteger al sujeto de investigación y, de manera especial, a los más vulnerables, estos aspectos deben ser objeto de una atenta consideración y evaluación que tienda hacia la corrección de los mismos. El artículo plantea también una estrategia a través de la ética del discurso y presenta objeciones a su eficacia procedimental.
\end{abstract}

Palabras clave: bioética, medicalización, vulnerabilidad, consentimiento informado

\section{BIOMEDICAL INVESTIGATION AND INFORMED CONSENT IN VULNERABLE POPULATIONS AND INDIVIDUALS}

\begin{abstract}
The economical and political transnationality context inside which today's biomedical investigations take place favours the phenomenon known as life's medicalization and raises both countries' and individuals' vulnerability. If we assume that the need to protect the subjects of investigation is bioethics' accepted responsibility, and, first of all, of the most vulnerable ones, these aspects should be taken into special consideration and evaluation in order to correct them, if needed.
\end{abstract}

Key words: bioethics, medicalization, vulnerability, informed consent

\section{A PESQUISA BIOMÉDICA E O CONSENTIMENTO INFORMADO NO ÂMBITO DAS POPULAÇÕES E INDIVÍDUOS VULNERÁVEIS}

Resumo: O contexto de transnacionalidade econômica e política em que se desenvolvem as atuais pesquisas biomédicas, favorece o conhecido fenômeno denominado medicalização" da vida e promove a vulnerabilidade, tanto dos países como dos indivíduos. Se levarmos em conta, que é responsabilidade assumida pela bioética, proteger o sujeito da pesquisa, e de maneira especial os mais vulneráveis, estes aspectos devem ser objeto de uma atenta consideração e avaliação, que vise a correção dos mesmos.

Palavras chave: bioética, medicalização, vulnerabilidade, consentimento informado

* Red de instituciones bioéticas del sudeste de la provincia de Buenos Aires Correspondencia: redsudeste@hotmail.com 


\section{Introducción}

La Red de Instituciones Bioéticas del Sudeste de la Provincia de Buenos Aires ${ }^{1}$ ha elaborado este documento a partir de inquietudes compartidas, en profunda discusión y posterior consenso dialógico, con la $\mathrm{ANMAT}^{2}$ (Administración $\mathrm{Na}$ cional de Medicamentos, Alimentos y Tecnología Médica) de la República Argentina, la que instaló en los miembros de la Red la pertenencia bioética del tema que aquí se desarrolla.

Desde un análisis descriptivo, nos proponemos poner en evidencia las particulares $\mathrm{y}$, en cierto sentido, novedosas condiciones de vulnerabilidad, tanto de comunidades como de individuos, en las que se desarrollan las actuales investigaciones biomédicas.

Somos parte de un mundo que transita una instancia transnacional, en donde los Estados, tradicionalmente reconocidos por sus límites geográficos, comienzan a desdibujarse en cuanto al real ejercicio de su soberanía. La globalización neoliberal se presenta a modo de "ley universal que responde naturalmente al devenir de los acontecimientos" y, como señala Bourdieu, tiene el poder de hacer advenir las realidades que pretende describir, según el principio de la profecía autocumplida.

1 Instituciones integrantes de la Red: Comités de HPC (Hospital Privado de Comunidad), del HIGA (Hospital General de Agudos) y del HIEMI (Hospital Interzonal Especializado Materno Infantil), del INAREPS (Instituto Nacional de Rehabilitación Psicofísica del Sur), de la Municipalidad de General Pueyrredón, de la Universidad Nacional de Mar del Plata, del Colegio de Médicos (Distrito X), del Colegio de Psicólogos, de la Asociación de Geriatría y Gerontología, de la Asociación de Genética Humana, de DIMED, del Centro Médico de Mar del Plata.

2 Los progresos tecnocientíficos en las ciencias de la salud demandan como exigencia para la aprobación de protocolos de investigación el control bioético de las innovaciones que proponen. En Argentina, en coincidencia con lineamientos propuestos por la Food and Drug Administration (FDA) y también con la Comunidad Económica Europea, ese control recae sobre la ANMAT, la que debe convalidar que los Protocolos de Investigación Científica tengan en cuenta las cuestiones bioéticas implicadas y las resuelvan en beneficio de los pacientes.
El poder real es ejercido por los grupos económicos que, actuando fuera del proceso electoral, hacen que las decisiones tomadas por los consorcios multinacionales y el gobierno consideren a la sociedad como un mero conjunto de sujetos de consumo. Más aún, cada individuo se convierte en un consumidor y/o espectador de la práctica política, donde el sujeto es tenido en cuenta a partir de los objetos materiales y/o culturales que consume. En tal situación, la democracia es un espectáculo que excluye a determinados individuos y grupos. Como expresa R. Castel, "para ser ciudadano hay que tener un mínimo de independencia y autonomía, no estar sometido a relaciones de clientelismo, de patronazgo. La función del Estado deberá responder preponderantemente a mantener la cohesión social en tanto asegure que el conjunto de sujetos, de grupos, estén unidos entre sí por relaciones de interdependencia. Emerge en este marco la dicotomía inclusión/exclusión, en donde lo último implica no sólo la carencia de atributos fundamentales para la inserción en el mercado, la falta de acceso a ciertos bienes/servicios y la condición de vulnerabilidad que presentan ciertos grupos, sino también la negación de ciudadanía, ya que significa, en otras palabras (...) carecer del derecho a tener derecho. Exclusión y desigualdad aparecen como parte de un "proceso histórico" a través del cual esta cultura occidental y mercantilista despoja a los individuos de su condición humana y les impide su ejercicio ciudadano. En este contexto, el fantasma de la exclusión social se cierne sobre los ciudadanos que reclaman a sus gobernantes el auténtico sentido de su ciudadanía política, civil, económica y social. Aparece en estas sociedades, altamente consumistas, un nuevo temor, transformado en fobia ${ }^{3}$ : el miedo a la exclusión y a la pobreza, que adopta la forma del "miedo al

3 El término fobia es empleado en su acepción etimológica correspondiente a miedo, temor, huida. 
pobre". No se le teme al anciano, sino a que éste sea pobre y por tanto una carga. No se le teme al extranjero, sino a su pobreza. Podría hacerse una extensa lista de fobias discriminatorias que, o bien enmascaran el temor o bien la apetencia por apoderarse de lo que el otro posee, incluido su patrimonio genético, su biología.

Esta situación configura otras condiciones de vulnerabilidad que incorporan al concepto tradicional nuevos aspectos. En tal sentido, distinguimos dos modalidades en la significación del término, a las que tipificamos como I y II.

I. El concepto tradicional, que coincide con la caracterización de Mancini Rueda ${ }^{4}$, se define del siguiente modo: "La vulnerabilidad se refiere a la acentuada incapacidad de una persona de proteger sus propios intereses debido a impedimentos tales como su imposibilidad para dar un consentimiento informado, no poder recurrir a otra forma de obtener atención médica o de satisfacer otras necesidades costosas, o ser un miembro de nivel inferior o subordinado de un grupo jerárquico". En tal sentido, señalamos como vulnerables a aquellos individuos, comunidades o sectores de la comunidad expuestos a padecer daño o abuso debido a que su autonomía se encuentra menoscabada o disminuida.

En términos generales, es suficientemente aceptado que la situación de este tipo de vulnerabilidad puede ser motivada por alguno/s de los siguientes factores:

- Ser menor de edad.

- Tener una grave discapacidad sensorial que dificulte la comprensión.

4 Mancini Rueda, Roberto. Normas Éticas para la Investigación Clínica. Disponible en http:/www.uchile.cl/ bioetica/doc/normas.htm
- No dominar el idioma con fluidez.

- Padecer algún trastorno psiquiátrico agudo o crónico.

- Padecer un grave deterioro cognitivo.

Las personas en las que se den alguna/s de estas condiciones ${ }^{5}$ reunirían características especiales y distintivas que los tornan vulnerables en extremo. Ello obliga a generar estrategias especiales para salvaguardar sus derechos, contando entre ellas la inclusión de sus allegados inmediatos en la práctica terapéutica.

II. Cabe admitir que las condiciones actuales generan, como se ha señalado, particulares situaciones en las que individuos y/o comunidades quedan disminuidos en su autonomía a partir de la imposición de estructuras económicas y sociales que determinan su exclusión en instancias decisivas para su propia salud y/o calidad de vida. Ya no se trata de dificultades que radican en limitaciones individuales, sino de condiciones resultantes de decisiones políticas que, desde los diferentes centros de poder, definen una situación de exclusión en relación con diversos aspectos que atañen a su derecho a la salud y al bienestar. Desde este punto de vista resulta adecuada la relación de esta idea de "vulnerabilidad" con la de "exclusión”, que Manuel Castells define como: "...el proceso por el cual a ciertos individuos y grupos se les impide sistemáticamente el acceso a posiciones que les permitirían una subsistencia autónoma dentro de los niveles sociales determinados por las instituciones y valores en un contexto dado. Tal posición suele asociarse con la posibilidad de acceder a un trabajo remunerado relativamente regular,

5 El estar o el sentirse enfermo es de por sí un factor de vulnerabilidad. 
al menos para un miembro de una unidad familiar estable ${ }^{6 \%}$.

Se configura así una condición de vulnerabilidad ante la cual las estrategias bioéticas habitualmente implementadas evidencian significativas limitaciones. A modo de ejemplo hacemos referencia a:

- Quienes no tienen posibilidades de acceder no sólo a las nuevas tecnologías, altamente sofisticadas y de elevado costo, sino que ni siquiera a las formas tradicionales y básicas del sistema sanitario. Ello se relaciona generalmente con su marginación del sistema productivo que los priva de su carácter de usuario, tanto de los sistemas sociales de salud como de las ofertas privadas.

- Aquellos que carecen de una formación educacional básica y no están preparados porque: o viven en la ignorancia de lo que ocurre, o se encuentran imposibilitados por desconocer los medios para defenderse, o por carecer de medios para su consecución.

- Quienes cuentan con el reconocimiento de su ciudadanía económica y, en general, tienen acceso al consumo, pero se transforman en vulnerables en la medida en que resultan víctimas del poder hegemónico que impone usos y costumbres de los países centrales, sin acceder a lo que tales poblaciones desarrolladas poseen.

En efecto, agotadas las promesas del Estado de Bienestar, quienes no tienen acceso a la información y a la cultura tampoco tienen acceso a plantear y defender sus derechos como usuarios/consumidores.

Resulta especialmente emblemática la situación de vulnerabilidad que se presenta en el

6 Castells M. La era de la información. Fin del milenio. Volumen III. México: Siglo Veintiuno Editores; 1997: 98. modo que adopta hoy la investigación biomédica; sobran los ejemplos de abusos en la historia de esta actividad, antes y después de Nuremberg, que instan a los principales organismos dedicados al control de medicamentos y de investigación clínica y terapéutica a tomar medidas serias para regularla más estrictamente, superando la tesis de la autorregulación.

Precisamente, uno de los compromisos fundamentales de la bioética tiene que ver con el resguardo de las personas ante las situaciones señaladas, incorporando dos consideraciones éticas fundamentales: la sustentación de la capacidad de autodeterminación y el respeto por la autonomía, y su contrapartida consistente en el resguardo contra el daño o el abuso de las personas cuya autonomía se encuentra menoscabada o disminuida.

El marco teórico más tradicional desde el cual la bioética podría abordar un problema como éste es el de la llamada "teoría de los principios" (beneficencia, no maleficencia, autonomía y justicia), tanto para la atención de la salud como para la investigación sobre sujetos humanos, en la que poderosos centros de poder tienen especial interés. En principio, cuenta para ello con el marco teórico que configura la ética de la comunicación, la estructura jurídica definida por los documentos y leyes que orientan sus aportes, y los procedimientos instrumentales tales como el consentimiento informado, que operacionaliza el ejercicio de la autonomía en las diversas instancias de la acción investigativa o terapéutica.

No obstante, cabe reconocer que estas estrategias ponen en evidencia serias dificultades; ello ocurre ante la posibilidad de intervenir con eficacia en las situaciones generadas por la profusa implementación de la investigación biomédica aplicada a individuos y comunidades afectados por alguno de los modos de vulnerabilidad mencionados, especialmente el descrito en el 
punto II, que desborda tanto el concepto como los intentos de solución tradicionales.

\section{Consentimiento informado}

El informe Belmont identificó los principios éticos básicos a tener en cuenta en la investigación biomédica y los llamó "de beneficio" (beneficencia-no maleficencia), "de respeto por las personas" (autonomía) y "de equidad" (justicia). El principio de beneficencia "se refiere a la obligación ética de lograr los máximos beneficios y de reducir al mínimo el daño y la equivocación (relación riesgo/beneficio). Este principio da origen a normas para que los riesgos de la investigación sean razonables frente a los beneficios previstos, que el diseño de la investigación sea acertado y que los investigadores sean competentes, tanto para realizar la investigación como para salvaguardar el bienestar de las personas que participan en ella”.

Pero también implica condenar todo acto que dañe deliberadamente a las personas, aun con el pretexto de un beneficio mayor (principio de no maleficencia). Debe existir, en efecto, proporcionalidad entre el bien buscado y el medio empleado. El principio de no maleficencia, según Diego Gracia, obliga a todos de modo primario y es, por lo tanto, anterior a cualquier tipo de información o de consentimiento.

Se consideran también los principios de autonomía, una de cuyas principales manifestaciones es el proceso de consentimiento informado, y de justicia, que requiere la selección equitativa de los sujetos de investigación.

Estos requerimientos los ha plasmado la comunidad médica internacional hace mucho en la declaración de Helsinki (1964) ${ }^{7}$, revisada

7 Declaración de Helsinki de la Asociación Médica Mundial, 1964. Copia disponible en http://www.uchile.cl/bioetica/doc/ helsink.htm periódicamente. La determinación de la competencia y la autonomía del sujeto debe quedar establecida antes de comenzar el estudio. En este marco, el consentimiento informado (CI) especifica, para el caso particular de la investigación, “...la adhesión libre y racional del sujeto a un procedimiento propuesto por el equipo de salud, sea con intención diagnóstica, pronóstica, terapéutica o experimental, e incluye competencia, información y libertad ${ }^{8 "}$.

Desde esta perspectiva el CI puede ser considerado una herramienta para incorporar al sujeto y/o a sus familiares o representantes a un proceso que reconoce sus intereses y les permite ponderar situaciones y elegir en consecuencia. Si nos centramos en esta definición, podemos comprender que cualquier acto médico realizado sin la previa autorización o consentimiento del enfermo puede constituir un delito contra la libertad del paciente.

Los requisitos fundamentales para que el CI sea válido son:

- El sujeto y/o el familiar responsable debe/n tener información médica suficiente para tomar una decisión adecuadamente sustentada.

- El consentimiento debe ser realizado por el sujeto y/o el familiar y/o tutor de forma voluntaria y sin presiones,

- El sujeto $\mathrm{y} / \mathrm{o}$ el familiar o tutor que otorga $/ \mathrm{n}$ el consentimiento debe/n tener competencia y capacidad suficientes.

- $\mathrm{Si}$ el sujeto es vulnerable, quien lo represente debe no serlo.

8 Manzini JL, Salvador H. La autonomía del sujeto y el consentimiento informado. Elemental análisis histórico y conceptual. Estado actual y perspectivas en la República Argentina. Quirón 1993; 24(3):40-7. 
- El consentimiento informado debe ser expresado fehaciente y formalmente respondiendo a la legalidad vigente.

- El consentimiento informado que resulte de un proceso gestado en relaciones simétricas debe tener una forma externa (verbal y/o escrita).

- El consentimiento informado debe ser obtenido con suficiente antelación a la realización del procedimiento.

Si bien estas pautas son claras, no siempre son suficientes, porque el contexto de transnacionalidad económica y política en el que se desarrollan las actuales investigaciones biomédicas favorece el fenómeno conocido como "medicalización" de la vida", que genera el aumento de lo percibido como "necesidad" en el campo de la salud, condicionando una dependencia que promueve la vulnerabilidad de países e individuos. La reflexión bioética demanda la búsqueda de nuevas estrategias para proteger a aquellas personas que, por factores de diversa índole, se hallen en condiciones de vulnerabilidad, y una de ellas es, sin duda, realizar consentimientos informados correctos desde perspectivas éticas superadoras, como la que se expondrá a continuación.

\section{Ética discursiva}

En cuanto marco teórico de estos procedimientos, la ética discursiva demanda que el consentimiento informado se efectúe a través de un diálogo válido, que posibilite el ejercicio intersubjetivo de la autonomía de todos los involucrados en el proceso que acompaña la toma de decisiones. Estos aspectos deben ser considerados y ponderados en la investigación biomédica si se pretende proteger al sujeto de investigación, garantizando no sólo el respeto de sus derechos sino también la beneficencia que debe guiar las acciones de los investigadores.
En este sentido, la ética discursiva sostiene que es esencial considerar a la razón moral como dialógica, instancia que no se agota en la pura conciencia y que se legitima en los discursos prácticos a través de la comunicación intersubjetiva, estableciendo normas de acción. La validez intersubjetiva de la norma hace entrar a la ética al campo de la racionalidad teórico-práctica, lo que permite abordar los conflictos, hacerlos públicos, discutirlos y consensuar su solución, posibilitando, además, que se tengan en cuenta los intereses de todos los afectados en circunstancias históricas concretas. Las normas situacionales, producto de los discursos prácticos, son fácticamente cuestionables. Sólo el principio procedimental conserva su validez incondicionada ${ }^{9}$.

Todo discurso práctico debe garantizar no sólo la representatividad de todos lo afectados, sino también la simetría de las partes en conflicto. Esta tarea se desarrolla cuando los discursos prácticos han sido institucionalizados $\mathrm{y}$ permiten la tematización y la compensación de las diferencias.

El concepto de "comunidad ideal", en la que todos tienen igual poder e igual derecho, funciona como idea reguladora de la comunidad real. En esta última, la autonomía sigue siendo "la capacidad del sujeto moral de decidir a favor de sus propios intereses", siempre que éstos hayan sido legitimados a través de una argumentación que tenga en cuenta los intereses de todos los otros involucrados en la toma de decisiones. Esa legitimación del ejercicio de la autonomía eleva la toma de decisiones a la categoría de mínimo universalizable. Lo que se legitima es aquello que, en condiciones de validez, quienes participan en la argumentación y los que están implicados en ella, considerarían como universalmente correcto.

9 Apel KO. Teoría de la verdad y ética del discurso. Barcelona: Paidós; 1991:160. 
Por eso la ética comunicativa considera que la autonomía es "competencia comunicativa", o que debe entenderse como capacidad de la persona por exponer y defender sus intereses en una comunidad de argumentantes. Allí debe respetarse la autonomía, pero también debe existir la capacidad por ponerse en el lugar del otro; deben tematizarse las asimetrías y compensarse las diferencias, pero con la convicción de que el diálogo puede llevarnos siempre al consenso entre todos los involucrados o, al menos, sentar las bases para que esto suceda. En este marco, la argumentación constituye un avance ético de envergadura, porque permite superar lo que se ha denominado el "paradigma de la conciencia", reconociendo la necesidad de la intersubjetividad en la construcción de las normas morales y una permanente falibilidad que implica, a la vez, la responsabilidad ética de revisarlas y consensuarlas legítimamente.

\section{Objeciones}

Pero a pesar de los aspectos mencionados, que se valoran como aciertos, se han manifestado objeciones importantes, a las que esta ética responde sólo parcialmente o no considera, y que constituyen puntos esenciales en la consideración de las poblaciones vulnerables que deben acceder al consentimiento informado; en este caso particular, en el ámbito de la investigación biomédica. Trataremos de sistematizarlas teniendo en cuenta la opinión de autores como Weber, Dussel, Ellacuría, Eze, entre otros.

\section{La comunidad ideal de argumentantes}

En esta comunidad los conflictos "siempre" pueden resolverse a través de argumentaciones racionales. El presupuesto que se denuncia es la presunción de que su carácter ideal la exime de revisión; pero lo "ideal" es, también, una construcción que conlleva valores que deben ser explicitados. La comunidad ideal de argumentantes se constituye a través de un esquematismo formal que oculta los valores que han impregnado su construcción. Por ejemplo, si se admite que existe la competencia perfecta, concebida como la situación ideal en la que el propio interés permite alcanzar el logro del bien común, es posible aceptar la imperfección de la competencia real que sólo persigue el propio beneficio. En cambio, en lugar de condenar las consecuencias indeseables de la competencia insolidaria se confía en que debe evolucionar hacia mejores formas.

Otro peligro consiste en legitimar situaciones que han respondido a determinados valores otorgándoles el rótulo de "naturales". Friedrich Hayek justifica la eliminación de todos los que son vencidos por la competencia del mercado, convencido de que es el único horizonte formal -racional- económico posible en el que se dirimen todas las cuestiones humanas, y esto es así porque responde al proceso de selección natural que regula a todos los seres vivos. Esta afirmación puede entenderse como la legitimación de la exclusión de los vencidos, incluidos los económicos, o, lo que es peor, como sancionar un principio de muerte que pone en peligro la humanidad entera.

Reconociendo estos peligros, Weber ha considerado que estas situaciones ideales, entendidas como utopías, generan una apariencia de realismo que puede encubrir la contingencia del mundo, sosteniendo la existencia de un mundo no-contingente al que deberíamos acercarnos. Esto es en realidad magia, es la ilusión trascendental de la modernidad.

\section{Inconmensurabilidad del lenguaje}

La ilusión antedicha también es extrapolable al lenguaje, ocultando su permanente ambivalencia y equivocidad. En la ética del discurso se ha supuesto que los conflictos pueden resolverse a través de argumentaciones ra- 
cionales que se explicitan en el diálogo, pero las redes simbólicas en las que se desenvuelve la vida humana impiden, muchas veces, que los intereses estimados reales por personas vulnerables y menos vulnerables (todos somos vulnerables en distintos grados y dimensiones) coincidan. $Y$ esto es así independientemente de las necesidades de cada uno de lograr el consenso racional. El significante, el plus de significación que se establece en toda comunicación, siempre supera la vinculación rígida y correspondentista del significado porque incluye valores no siempre compartidos que producen desplazamientos de sentido.

Creemos, con Apel, que las argumentaciones racionales dan validez al diálogo, pero es necesario considerar y analizar también el proceso complementario realizado por el resto de las capacidades humanas que están en juego en el quehacer comunicativo y las historias de vida que condicionan a los sujetos que dialogan. El diálogo puede ser posible si las personas, además de creer que lo es, entienden lo que se dice, tratando de superar ciertos aspectos inconmensurables de la comunicación. La definición de persona desde la ética del discurso se centra en la posibilidad de todos los hombres de ser "interlocutores válidos". Sin embargo, se ha objetado que no todos ellos son capaces de expresar sus intereses, sobre todo si su integridad, de la cual depende su autonomía, ha sido disminuida o cercenada, es decir, si se trata de individuos condicionados por algún modo de vulnerabilidad.

Además, la vida humana se configura y desenvuelve en el nivel simbólico, convenido de manera particular por cada grupo social. Por ello, es necesario indagar por el sentido que se le ha otorgado, que puede ser diferente en cada cultura, ya que la característica del fenómeno simbólico es la indeterminación.

\section{Cuestionamiento a la racionalidad occidental y a una noción reduccionista del sujeto}

Alrededor de los años 70, década que coincide con el nacimiento de la bioética, comienza a gestarse una crítica a la universalidad de la razón moderna, llevada a cabo, entre otros, por Foucault, Deleuze, Derrida, Lyotard y Vattimo. Sin embargo, quienes desconfían del irracionalismo piensan que es necesario complementar la tarea de la modernidad, sin renunciar a la razón. En esa línea se encuentran Apel, Habermas y Ellacuría, empeñados en combatir el escepticismo pragmatista, especialmente el norteamericano.

Ellacuría y Apel, por ejemplo, coinciden en que la actual forma de vida occidental ${ }^{10}$ no es universalizable, ya que su permanencia compromete la supervivencia de la humanidad. Ambos reconocen que esto constituye un grave problema ético pero llegan a avizorar consecuencias éticas diferentes. Apel estima que los pueblos pobres deberían cuestionar su pretensión de imitar a los pueblos ricos y buscar, en cambio, un camino propio que no comprometa la vida del planeta. Ellacuría sostiene, en cambio, que el modo de vida occidental debe ser declarado inmoral y que quienes deben corregir sus pretensiones son los pueblos desarrollados, cuestionando las instituciones vigentes hasta que su forma de vida se vuelva universalizable.

Para la ética discursiva, renunciar a las instituciones es desprenderse de una forma de vida que contiene las condiciones de posibilidad del discurso práctico. El diálogo en la ética discursiva es la fuente de la que manan todos los valores, de ahí que sería poco responsable

10 Marcada por el modelo de desarrollo predominantemente mercantilista financiero tecnoligizante que puede llevar a la destrucción de la humanidad 
cuestionar las instituciones que lo posibilitan. La controversia queda entonces planteada: asumir la defensa de la universalidad o aceptar la afirmación de las diferencias culturales.

La filosofía de la liberación, propuesta por E. Dussel, pretende mediar entre las posiciones extremas, ya que adopta una visión crítica respecto de la "razón moderna" proponiendo una racionalidad diferencial y universal. La afirmación y emancipación de la diferencia va construyendo una universalidad novedosa y futura. La cuestión no es "diferencia o universalidad", sino universalidad en la diferencia y diferencia en la universalidad ${ }^{11}$.

\section{La conflictividad como elemento que garantice reconocer la diferencia}

La ética del discurso exige a los miembros de la comunidad real de argumentantes resolver los conflictos y lograr siempre consensos en condiciones de validez. Eze, filósofo africano, piensa que si lo racional es el consenso deberíamos considerar irracionales a todas las luchas de intereses, que son las que permiten desarrollar estructuras individuales de deseos, única garantía contra la ambición de poder y dominación. Como la condición humana no puede, en principio, garantizar la posibilidad de una justicia absoluta, entonces las luchas y los conflictos no siempre son evidentemente irracionales.

La noción de consenso parece enriquecerse cuando se presenta no sólo como el resultado de los participantes de una comunidad de comunicación, sino que incluye el proceso mismo por el cual los no incluidos en ella logran trasponer y extender sus límites. Para Dussel, el otro puede esgrimir razones nuevas que obliguen a reconsiderar los acuerdos y consensos ya tomados.

11 Dussel E. La filosofia de la liberación ante el debate de la postmodernidad. Los estudios latinoamericanos. Puebla.
Sin negar que la búsqueda del consenso puede y debe constituir un proceso dialógico, que permita una mediación necesaria en la búsqueda de soluciones a los problemas que afectan a la humanidad y al planeta entero, este consenso pierde efectividad en tanto garante de justicia si la comprensión del mundo que le sirve de marco se postula como una proyección globalizada, cuando en realidad es una particular compresión del mundo. No basta con partir del nosotros; es necesario afirmar éticamente al otro.

\section{La vulnerabilidad condiciona la asimetría del diálogo}

La vulnerabilidad se vive aun antes de tener conciencia de ella. Si la integridad de los sujetos ha sido vulnerada, aunque se les permita manifestar sus intereses éstos reflejarán esa vulnerabilidad. Marx propone seguir el imperativo categórico de echar por tierra todas las relaciones en las que el hombre sea un ser humillado, sojuzgado y subordinado, abandonado y despreciable.

Si el otro es excluido e ignorado, ¿cómo sabemos si su razón cuestiona lo acordado? Dussel, en "Ética de la Liberación" propone: "El que actúa éticamente debe (como obligación) producir, reproducir y desarrollar autorresponsablemente la vida concreta de cada sujeto, contando con enunciados normativos con pretensión de verdad práctica, en una comunidad de vida (desde una vida "buena" cultural e histórica, con su modo de concebir la felicidad, en una cierta referencia a valores y a una manera fundamental de comprender el ser como el deber ser, por ello con pretensión de rectitud también) que se comparte pulsional y solidariamente, teniendo como horizonte último a toda la humanidad, es decir, con pretensión de universalidad ${ }^{12}$ ".

12 Dussel E. ¿Es posible un principio ético material, universal y crítico? México; UNAM; 1997. 
Dussel sostiene que este principio universal constituye un punto de partida histórico, dado que buena parte de la humanidad no puede vivir o no puede desarrollar la vida de una manera cualitativamente aceptable.

Si la vida humana es el criterio de verdad (además de validez y factibilidad), la no-posibilidad de que las víctimas vivan, es ahora el criterio crítico-ético por excelencia. El hecho de que esta víctima no pueda empíricamente vivir, es criterio de juicio suficiente (en última instancia) para denunciar que el sistema que la victimiza no puede ser verdadero (reproducir la vida), ni válido (porque ha sido excluida del discurso), ni factible o eficiente (al menos es ineficiente en la reproducción de la vida de esta víctima).

\section{El carácter formalista del principio procedimental}

La consideración de la ética priorizando el procedimiento contractualista o discursivo ha sido considerado por autores como Alasdair MacIntyre y Bernard Williams como insuficiente, puesto que, desde allí, se acentúan las dimensiones deontológicas de la acción moral, relegando el mundo de los fines, sin los cuales ésta no tendría sentido, a un papel incidental.

El principio formal que regula los discursos prácticos nada nos dice de las máximas y valores que cada interlocutor válido defendería como deseables en el marco de las instituciones y organizaciones donde se realiza el discurso. Es necesario moralizar la acción colectiva en las que se relacionan vulnerables y poderosos a través de prácticas morales que impliquen el desarrollo de lo que en la concepción aristotélica se ha denominado "virtud".

Las virtudes, consideradas en el pensamiento tradicional como las disposiciones subjetivas requeridas por toda acción moral, deben ser ejer- cidas por los sujetos morales que actúan en los discursos prácticos, en los que se definen intersubjetivamente los valores y normas a las que van a ajustarse. La virtud debe ser entendida como un hábito elegido para acceder a la contextualidad en la que se está inmerso; no es ni capacidad dada ni pasión ${ }^{13}$, sino posibilidad activa del sujeto moral que debe ser construida. El ejercicio de las virtudes conforma una sensibilidad moral factible de ser educada y modificada y, a la vez, capacita al sujeto moral para percibir y comprender la complejidad de los actos morales. Sin tales disposiciones activas de los sujetos, la situación discursiva sería imposible. Esta construcción personal se realiza en la comunidad moral a la que se pertenece y en donde se desarrollan dimensiones que constituyen una práctica moral, tal como fue definida por MacIntyre: “...actividad cooperativa que cobra su sentido - su racionalidad específica- persiguiendo determinados bienes internos, lo cual exige el desarrollo de determinados hábitos por parte de quienes participan en ella".

La generación de hábitos morales en los sujetos puede reducir significativamente las condiciones que generan vulnerabilidad y complementar la estrategia procedimental propuesta por la ética discursiva. Considerando que las investigaciones biomédicas requieren, como toda acción social, procedimientos y prácticas morales que guíen su desarrollo, se hace necesario considerar, tal como lo propone Adela Cortina, el tratamiento de distintas dimensiones de las estructuras socioculturales:

a) Elaborar metas sociales en las que la acción de los ciudadanos cobre sentido y las investigaciones biomédicas sean valoradas intersubjetivamente.

b) Generar los mecanismos adecuados para alcanzarlas en los distintos tipos de sociedad.

13 Aristóteles. Ética a Nicómaco. Libro II, (1106 A). 
c) Construir un marco político-jurídico, expresado en la Constitución y la legislación complementaria vigente.

d) Posibilitar una moral crítica que se lleve a cabo en una práctica social que contemple la educación y el ejercicio de virtudes morales.

e) Posibilitar una moral crítica que ponga en práctica los procedimientos planteados por la ética discursiva.

Si los procedimientos y los hábitos morales pudieran complementarse adquiriendo significatividad y legitimación social, las organizaciones que llevan adelante la investigación biomédica podrían ser más eficaces en la prosecución de sus fines, ya que estos encarnarían valores consensuados en procesos históricos concretos, que darían lugar a normas morales mínimas universalizables.

\section{Marco jurídico}

Desde el ámbito del Derecho, se reconoce que la expansión de las fronteras del conocimiento ha posibilitado el mejoramiento de las condiciones de vida de la humanidad pero, también, ha generado un potencial destructivo de consecuencias aún no suficientemente ponderadas.

El campo de la salud no ha sido ajeno a este problema y requiere un tratamiento que incorpore una perspectiva ética y jurídica capaz de orientar nuevos cursos de acción. En el campo de la investigación con seres humanos, quienes defienden la neutralidad valorativa de la ciencia ven debilitados sus argumentos cuando se les muestra que, en general, son los laboratorios medicinales los que imponen las líneas y diseños que después los investigadores adoptan en el campo de la salud. Ciertamente, sin tecnología de base no se produce investigación científica ni se pueden poner a prueba las hipótesis; pero la tecnología requiere fuertes inver- siones económicas que pretenden ser recuperadas con creces y que sesgan la dirección del desarrollo de la ciencia.

En cuanto al contexto económico, el gasto total mundial en medicamentos es de varios cientos de miles de millones de dólares. El análisis de esta inmensa erogación pone en evidencia las grandes desigualdades existentes entre los países pobres y ricos. Aproximadamente el $70 \%$ del gasto en medicamentos se consume en los llamados países desarrollados de América del Norte y Europa Occidental.

El mercado farmacéutico mundial (también el de Argentina) se ha incrementado abruptamente, generando, además de múltiples beneficios, consecuencias no deseadas que a veces derivan del uso irracional de los medicamentos. Estas circunstancias se han comenzado a evaluar no hace mucho tiempo y se hizo imprescindible establecer una relación entre los objetivos de la salud pública y una normativa que traduzca los principios éticos jurídicos tendientes a proteger dichos objetivos.

\section{Conclusión}

Las cuestiones consideradas ponen en evidencia que la investigación biomédica realizada en poblaciones vulnerables agudiza las limitaciones de las estrategias que la bioética ha puesto en marcha, tanto desde el ámbito teórico como desde el jurídico y operativo, mostrando la complejidad del fenómeno desde las actuales condiciones de la cultura de la globalización. Al menos en su aplicación, ésta tiene como un correlato, al parecer ineludible, la exclusión que se manifiesta en diferentes y complejos modos de vulnerabilidad.

Como se ha señalado, se reconoce que el consentimiento informado constituye un importante avance en el contexto de las relaciones intersubjetivas; no obstante, hay espacios de la 
comunicación y de la culturización en los que su implementación, aunque adecuada, no garantiza el ejercicio de un auténtico poder de decisión de quienes participan en los innumerables y no siempre adecuadamente controlados proyectos de investigación biomédica.

Surgen también objeciones que no pueden ser respondidas desde la ética discursiva, porque su propuesta de corte racionalista no puede dar cuenta de toda la complejidad de los fenómenos sociales. En este sentido se han señalado algunas limitaciones cuyo análisis puede generar un proyecto superador que permita reconsiderar el papel de la comunidad ideal de argumentantes, reflexionar sobre el impacto de los aspectos inconmensurables del lenguaje en la comunicación, posibilitar la defensa de una noción no reduccionista de sujeto y examinar la incidencia de la vulnerabilidad en la consolidación de las asimetrías, cuestiones no resueltas por la ética discursiva. También es necesario considerar el papel que debiera cumplir la educación moral en la formación de sujetos virtuosos, capaces de seguir aquellas normas consensuadas en las comunidades morales que les posibiliten alcanzar una "vida buena".

Si bien el Derecho no ha podido asegurar, a pesar de las normativas vigentes, que las investigaciones realizadas en seres humanos res- peten el derecho a la información (condición necesaria para el ejercicio de la autonomía) y a la no coerción explícita o implícita, la lectura jurídica deberá esforzarse para posibilitar que los conflictos de intereses se resuelvan en favor de quienes se hallan más indefensos.

El nuevo enfoque destaca la constitución de actores y la generación de movimientos sociales para plantear una agenda social con nuevas prioridades, basadas no sólo en la minimización de los costos -eficiencia/eficacia-, sino también centradas en las preocupaciones humanas, la participación, el ejercicio de las virtudes y la definición del sentido de justicia. Esta sería una nueva construcción en la que el poder debe descentrarse y otorgar mayor participación a la sociedad, lo que revestiría de sentido a los órganos gubernamentales representativos, hoy desvirtuados. También daría cabida, así, a un sujeto reformista y autónomo que haría valer su fragmentación como una forma de dar espacio a los distintos intereses de los grupos sociales pero, a la vez, podría elaborar intersubjetivamente metas sociales consensuadas por el ejercicio de una moral crítica que fundamente los procedimientos y las prácticas llevadas a cabo, de manera especial en las investigaciones biomédicas que constituyen un fenómeno complejo que requiere de la máxima atención.

\section{Bibliografía}

Amin S. Capitalismo, Imperialismo, Mundialización. En: Seoane J, Taddei E, (comp.) Resistencias Mundiales. Buenos Aires: CLACSO; 2001.

Apel KO. Una ética de la responsabilidad en la era de la ciencia. Buenos Aires: Almagesto; 1984

Apel KO. Teoría de la verdad y ética del discurso. Barcelona: Paidós; 1991.

Apel KO. Semiótica filosófica. Buenos Aires: Almagesto; 1994.

Bendesky L. La economía regional en la era de la globalización. Comercio Exterior 1994; 44.

Castells M. La era de la información. Fin del milenio. Volumen III. México: Siglo Veintiuno Editores; 1997. 
Castel R. De la peligrosidad al riesgo. En: Varela J, Álvarez U, (eds.) Materiales de sociología crítica. Madrid: La Piqueta; 1986

Cechetto S. Teoría y práctica del consentimiento informado en el área neonata. Mar del Plata: Ediciones Suárez; 2001.

CIOMS Normas éticas internacionales para las investigaciones biomédicas con sujetos humanos. Ginebra: Consejo de Organizaciones Internacionales de las Ciencias Médicas; 1996.

Cortina A. Ética sin moral. Madrid: Tecnos; 1990.

Deleuze G. Post-scriptum sobre las sociedades de control. En: Deleuze G. Conversaciones 1972-1990. Valencia: Pre-Textos; 1995.

Dussel E. ¿Es posible un principio ético material, universal y crítico? México: UNAM; 1997.

Dussel E. La filosofía de la liberación ante el debate de la posmodernidad. Puebla: Los Estudios Latinoamericanos; 1999.

Foucault M. Saber y verdad. Madrid: La Piqueta; 1991.

Gracia D. Los fundamentos de la bioética. Madrid: Eudema; 1989.

Habermas J. Escritos sobre moralidad y eticidad. Barcelona: Paidós; 1991.

Lipovetsky G. El crepúsculo del deber. La ética indolora de los nuevos tiempos democráticos. Barcelona: Anagrama; 1996.

Luna F, Salles, A, (comp.) Bioética: investigación, muerte, procreación y otros temas de ética aplicada. Buenos Aires: Editorial Sudamericana; 1998.

Macintyre A. Tras la virtud. Barcelona: Crítica; 1987.

Mainetti JA. Ética médica. La Plata: Quirón; 1989.

Maliandi R. Ética: conceptos y problemas. Buenos Aires: Biblos; 1991.

Maliandi R. Volver a la razón. Buenos Aires: Biblos; 1997.

Manzini JL, Salvador H. La autonomía del paciente y el consentimiento informado. Buenos Aires: Quirón; 1993: 40-47.

Pellegrino E. La relación entre la autonomía y la integridad en la ética médica. En: Bioética. Temas y perspectivas. Washington DC: Organización Panamericana de la Salud; 1990. Publ. Científica No 527.

Zeneca F. Principios básicos de investigación clínica. Madrid: Ediciones Ergon S.A.; 1993. 